\title{
Quantification of Mouse Lung Elastin During Prenatal Development
}

\author{
Paula Rodrigues ${ }^{1}$, Carlos Gonçalves ${ }^{*}, 2$, Ana Honório ${ }^{3}$, José Barros ${ }^{4}$ and Vasco Bairos ${ }^{5}$
}

\author{
${ }^{I}$ Department of Pathology and Veterinary Clinics - University of Trás-os-Montes e Alto Douro, (UTAD) Vila Real, Por- \\ tugal; Center for Animal and Veterinary Sciences, UTAD, Vila Real, Portugal \\ ${ }^{2}$ Institute of Histology and Embryology, Faculty of Medicine of Coimbra, Portugal; Center for Histophysiology, \\ Experimental Pathology and Developmental Biology, Faculty of Medicine of Coimbra, Portugal; Service of \\ Neonatology, Hospital of the University of Coimbra, Portugal \\ ${ }^{3}$ Institute of Histology and Embryology, Faculty of Medicine of Coimbra, Portugal \\ ${ }^{4}$ Center for Histophysiology, Experimental Pathology and Developmental, Biology, Faculty of Medicine of Coimbra, \\ Portugal; Service of Obstetrics, Hospital of the University of Coimbra, Portugal \\ ${ }^{5}$ Institute of Histology and Embryology, Faculty of Medicine of Coimbra, Portugal; Center for Histophysiology, \\ Experimental Pathology and Developmental Biology, Faculty of Medicine of Coimbra, Portugal
}

\begin{abstract}
Elastic fibres play a crucial function during the process of lung alveolisation. During the perinatal period, any changes in the elastogenic process during foetal development may result in permanent lifetime defects. In pre-natal life, well-developed pulmonary elastic fibres should favor the pre-natal maturation of the lung and an enhanced alveolisation, which in many species, such as humans begins only after birth. The authors present a quantitative study by image analysis and by high-pressure liquid chromatography (HPLC) of the mouse lungs' elastic fibre content from the 15th till the 19th gestational day.
\end{abstract}

Keywords: Lung development, elastic fibres, elastin, desmosin.

\section{INTRODUCTION}

The role played by elastic fibres in normal septal development through out the process of lung alveolization is an extremely vital and important one. The function of the elastic fibres as one of the structures supporting the secondary septa during the alveolisation period has been suggested by the temporal association between the appearance of bundles of elastic fibres at the tips of the secondary septa and the formation of new alveoli [1-3].

During the perinatal period, factors disturbing elastin synthesis or the assembly and maturation of elastic fibres lead to respiratory failure, not only due to the collapse of the mechano-expansive properties of the lung, but also because of abnormal lung development with deficient distal branching and alveolisation [4-8]. In pre-natal life, well-developed pulmonary elastic fibres should favor the pre-natal maturation of the lung and an enhanced alveolisation, which in many species, such as humans begins only after birth.

During foetal development, elastin is expressed in a temporally and spatially regulated pattern [9-12]. This fact, along with elastin's slow turnover makes it so that any changes in the elastogenic process during foetal development may result in permanent lifetime defects.

*Address correspondence to this author at the Institute of Histology and Embryology, Faculty of Medicine of Coimbra, 3004-504, Coimbra, Portugal; E-mail: carlos.condeixa@gmail.com; carloscond55@hotmail.com
In order to better understand the role of the pulmonary elastic fibres' system in lung physiology and pathophysiology, it is vital to know the fibers content and proportions, from an early foetal age. The authors present a quantitative study by image analysis and through the chemical determination of desmosine and isodesmosine through HPLC analysis of the mouse lung's elastic fibres throughout pre-natal development, from the $15^{\text {th }}$ till the $19^{\text {th }}$ gestational days. This period comprises the pseudoglandular, canalicular and terminal sac periods of mouse lung development [13].

\section{MATERIALS AND METHODS}

\section{Animals}

Adult mice from the ICR strain purchased from "Inter-

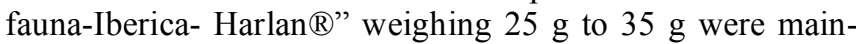
tained in a standard diet and water ad libitum. The females were mated overnight, for a period of $15 \mathrm{~h}$, in a polygamic regime. In the following morning the females presenting a vaginal plug were caged separately; this day was considered to be day 0 of gestation.

The gestation period of the IRC mice strain is 19 days. Our study occurs during this pre-natal period.

From the $15^{\text {th }}$ gestational day to the $19^{\text {th }}$ day of gestation, daily, four pregnant mice were deeply anaesthetized through an intramuscular injection of ketamin and xylazin $(50 \mathrm{mg} / \mathrm{kg}$ each) and the foetuses were collected and dissected. Foetal lungs were removed from the thorax and either fixed by immersion in a $10 \%$ formaline solution in $0.1 \mathrm{M}$ phosphate 
buffer, or washed in a saline solution, weighed and freezed at $-80{ }^{\circ} \mathrm{C}$ until biochemical processing.

\section{Quantification of Lung Elastin by Image Analysis}

The processing of the material for image analysis was performed according to Gonçalves et al. [14].

For the quantification by image analysis, for each gestational day studied, four lungs belonging to two foetuses from different litters with different progenitors were selected. After a 6 to 12 -hour fixation period, the foetal lungs were processed and paraffin embedded individually and cut in $4-\mu \mathrm{m}$ thick serial sections. From each block, two consecutive sections with paracoronal representation of all pulmonary lobes were chosen. One section was stained with the haematoxylin-eosin method (H-E), the other with the Gomori aldehyde-fucsin method for elastic fibre staining [15] omitting the nuclear counterstaining step. The slides were analysed with a Joyce-Loebl Mini Magiscan (Joyce-Loebl, Ltd, Gateshead, England) computerized image analysis system. The components of the image system included a video camera, Sony CCD AVC D-5CE, connected to a Nikon-Optiphot microscope with an $\mathrm{x} 40$ apochromatic lens $(0.85$ N.A.) and a computer with the Genias software (Joyce-Loebl, Ltd.), with a resolution of $512 \times 512$ pixels, which could discriminate between 64 different gray levels.

For each slide five images were acquired both in the Gomori stained sections and in the H-E ones, in a total of 40 images per studied day, 20 for each staining method.

The digitalized images were converted into binary images after selecting the suitable segmentation level. The binary images obtained from the Gomori stained slides were used to calculate the percentage of the area occupied by the elastic fibres. From the images acquired from the H-E stained slides we obtained binary images that allowed us to calculate for each field the percentage of the area occupied by the pulmonary tissue. By dividing the number of pixels corresponding to the area occupied by the elastic fibres by the number of pixels representing the area of the lung tissue we obtained the elastic fibres' volumetric density [16].

\section{Desmosine and Isodesmosine Quantification by HPLC}

\section{Preparation of the Stock Solutions}

One desmosine and one isodesmosine (EPC-Elastin Products CO., Inc.) stock solutions were prepared in $0.01 \mathrm{M}$ hydrochloric acid with a final concentration of $2 \mu \mathrm{mol} / \mathrm{ml}$.

Aliquots $(0.1 \mathrm{ml})$ of desmosine and isodesmosine solutions and of a standard mixture of aminoacids (Sigma AA-S18) at a concentration of $2.5 \mu \mathrm{mol} / \mathrm{ml}$ were diluted into $2 \mathrm{ml}$ with $6 \mathrm{M}$ hydrochloric acid and processed according to the cellulose minicolumn method [17], which will be described later.

\section{Elastin Extraction}

After being weighed, the lungs were collected, frozen, lyophilised, and dried at $+40^{\circ} \mathrm{C}$ under vacuum. Because of the small dimensions of the foetal lungs, for each analysed day a pool of lungs representing 23 to 34 individuals, belonging to four different litters were made (see Table 1).
Dried lung samples were homogenized in $2 \mathrm{ml}$ of water for 30 seconds at $+4^{\circ} \mathrm{C}$. The homogenate was mixed with an equal volume of a $10 \%(\mathrm{w} / \mathrm{v})$ cold trichloroacetic acid (TCA) solution and centrifuged at $9000 \mathrm{~g}$ for 10 minutes at $+4^{\circ} \mathrm{C}$. The supernatant was discarded and the residue treated with 5 $\mathrm{ml}$ of $5 \% \mathrm{TCA}$ at $+90^{\circ} \mathrm{C}$ for 30 minutes for the collagen to be extracted [18]. This material was centrifuged at $9000 \mathrm{~g}$ for 10 min. at $+4^{\circ} \mathrm{C}$, and the supernatant discarded. The TCA extracted residue was washed twice in $2.5 \mathrm{ml}$ acetone, followed by centrifugation at $9000 \mathrm{~g}$. The residue was dried at $+60^{\circ} \mathrm{C}$ under vacuum, and this final product constitutes a sample of protein with an elevated percentage of elastin.

\section{Elastin Hydrolysis}

Hydrolysis of the elastin from the samples and the standards was performed under an argon atmosphere in flamedsealed vials with $6 \mathrm{M}$ hydrochloric acid at $+120^{\circ} \mathrm{C}$ for 48 hours.

\section{Desmosines Purification by a Cellulose Minicolumn}

The isolation of desmosine in an almost pure form was attained by using a small column of cellulose [17]. Minicolumns were made from disposable plastic Pasteur pipettes by cutting off the top hemisphere of the bulb, which became a 4 $\mathrm{ml}$ solvent reservoir. The tip of the pipettes was plugged with a small quantity of fibreglass. A slurry was prepared by mixing $1 \mathrm{~g}$ cellulose with $20 \mathrm{ml}$ of the mobile phase, $\mathrm{n}$ butanol: acetic acid: water $(4: 1: 1)$. The previous hydrolyzed sample was mixed in order of addition with acetic acid $(0.5$ $\mathrm{ml})$, cellulose slurry $(0.5 \mathrm{ml})$, and $\mathrm{n}$-butanol $(2 \mathrm{ml})$. This mixture was introduced in the previously prepared column and the vial washed with $1.5 \mathrm{ml}$ mobile phase, which was also transferred to the column, and then eluded with $2 \mathrm{ml}$ of mobile phase. The desmosine and isodesmosine were eluted from the column with $5 \mathrm{ml}$ of pure water. The aqueous fraction containing the desmosines was lyophilised before analysis in order to remove residual butanol and acetic acid and to concentrate the sample.

\section{Precolumn Derivatization of Desmosines}

The precolumn derivatisation of desmosines was carried out according to a slight modification of the method of Guida and colleagues [19]. The previous lyophilised sample was dissolved in $1 \mathrm{ml}$ of hydrochloric acid, $0.01 \mathrm{M} .100 \mu 1$ of $0.5 \mathrm{M}$ sodium hydrogen carbonate in HPLC-grade water, and $100 \mu 1$ of $20 \mathrm{mM}$ Dansyl (DNS) chloride in acetone were added to $100 \mu 1$ of the sample. After 40 minutes at $+65^{\circ} \mathrm{C}$ in the dark, the derivatization mixture was diluted to $1 \mathrm{ml}$ with the mobile phase. The same derivatization procedure was carried out for the working standard solution. Volumes of $100 \mu 1$ of derivatization mixtures were injected into the chromatograph.

\section{Chromatographic Separations by HPLC}

Chromatographic separations were performed using an HPLC system, in which the loop was substituted for a Guard-Pak C18 module used as a precolumn and as an oncolumn enrichment sample device [19] and separated on a Spherisorb S5 ODS (150x4 mm, ID) column. In brief, desmosine and isodesmosine concentrations were determined by reverse-phase HPLC with a binary gradient elution: a mobile phase A, which was a 85: $15(\mathrm{v} / \mathrm{v})$ mixture of $25 \mathrm{mM}$ potas- 
sium dihydrogenphosphate and $25 \mathrm{mM}$ acetic acid: acetonitrile, and a mobile phase B, the same mixture but in a 40: 60, $v / v$, proportion. The mobile phases were degasified and the $\mathrm{pH}$ adjusted to 7.2. The mobile phases were held first at a gradient of $70 \%$ phase A and $30 \%$ phase B for $10 \mathrm{~min}$, and then to $65 \% \mathrm{~A}-45 \% \mathrm{~B}$ for $15 \mathrm{~min}$ at a constant flow rate of $2 \mathrm{ml} / \mathrm{min}$.

The detector was adjusted to read at $254 \mathrm{~nm}$, and quantification was performed by external calibration. The calibration curve was constructed by analysis of standard solutions containing scalar amounts of desmosines from $10 \mathrm{pmol} / \mathrm{ml}$ to $100 \mathrm{pmol} / \mathrm{ml}$.

\section{Statistical Analysis}

The data are expressed as mean \pm standard error (SE). The normal distribution of image analysis data obtained each analysed day was checked using the Kolmogorov-Smirnov normality test provided by "StatView ${ }^{\circledR}$ v.5.0" program (SAS Institute Inc.). The effect of gestational age upon morphometric and biochemical analysis was studied using ANOVA and by Scheffé's multiple comparison test. Differences were considered significant at $\mathrm{P}<0.05$. Correlation analysis was also made.

\section{RESULTS}

\section{Light Microscopy Observation}

By means of the used histological method, we demonstrated in a very selective way with no background staining the presence of elastic fibres in foetal lungs, even the most sparse and fine ones, as can be observed in Figs. (1A, 2).

In 15-days-old foetuses the lung had the characteristic morphology of the pseudoglandular stage of development, with a main lobar bronchial tube branching in a system of secondary and terminal ducts, surrounded by undifferentiated mesenchyme (Fig. 1). Pulmonary elastic fibres were seen only in association with the mesenchyma - prospective muscle layer - that closely envelops the bronchial tubes and in the secondary tubes at a short distance from their emerging point. The elastic fibres associated with the future respiratory tree were thin, short and poorly branched, sometimes forming a delicate, almost undetectable web.

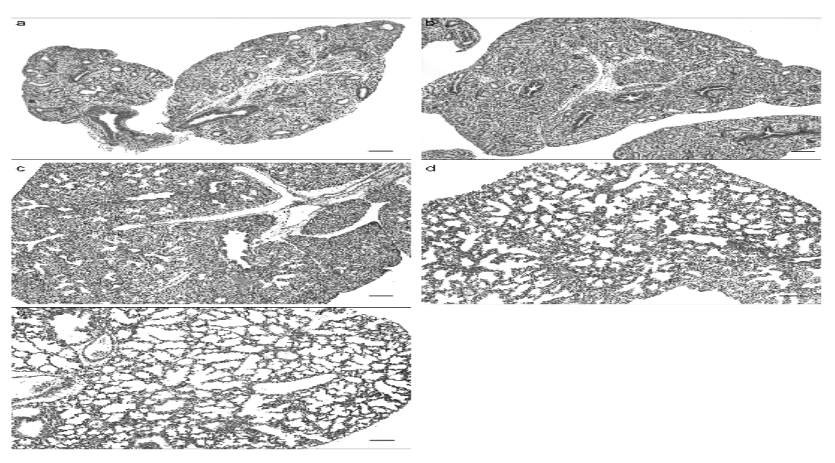

Fig. (1). Histological images from day 15 of gestation (a) to 19 day (e), the last day of gestation. H\&E staining. Barr $100 \mu \mathrm{m}$.

In contrast, the larger vessels, particularly arteries, were surrounded by a well-defined ring of elastic fibres delineating the prospective elastic membranes (Fig. 1A). In the lungs from the $16^{\text {th }}$ gestational day there is a strong increase in pulmonary elastic fibres, both in number and thickness, but only remaining in association with main and secondary bronchial tubes.

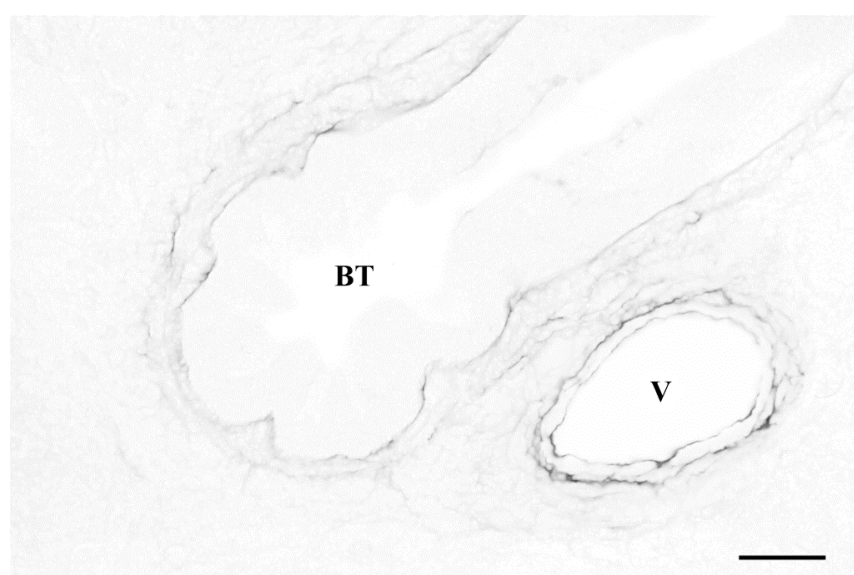

Fig. (1A). Histological image from a fetal lung on the 15th day of gestation stained by Gomori method. Elastic fibers of the bronchial tube (BT) wall are much thinner than around vessels (V). Note the delicate fibers between the two structures. Barr $=25 \mu \mathrm{m}$.

By the $17^{\text {th }}$ gestational day there was a strong change in the elastic fibre pattern in comparison with the other days. Apparently, there was not only a strong reduction in terms of quantity, but also the ones that could be seen were appeared disorganised and fragmented. This aspect was all the more unexpected as the lungs from the $18^{\text {th }}$ day revealed a welldeveloped elastic fibre web, which although apparently discontinuous, extended from the main lobar tube to the terminal ducts and to the emerging walls of the septa of the primitive alveolar saculli which begin to form at this stage of development. The lungs from the last gestational day showed an increase in the number and thickness of elastic fibres, particularly in the septa of the prospective alveolar sacs (Fig. 2).

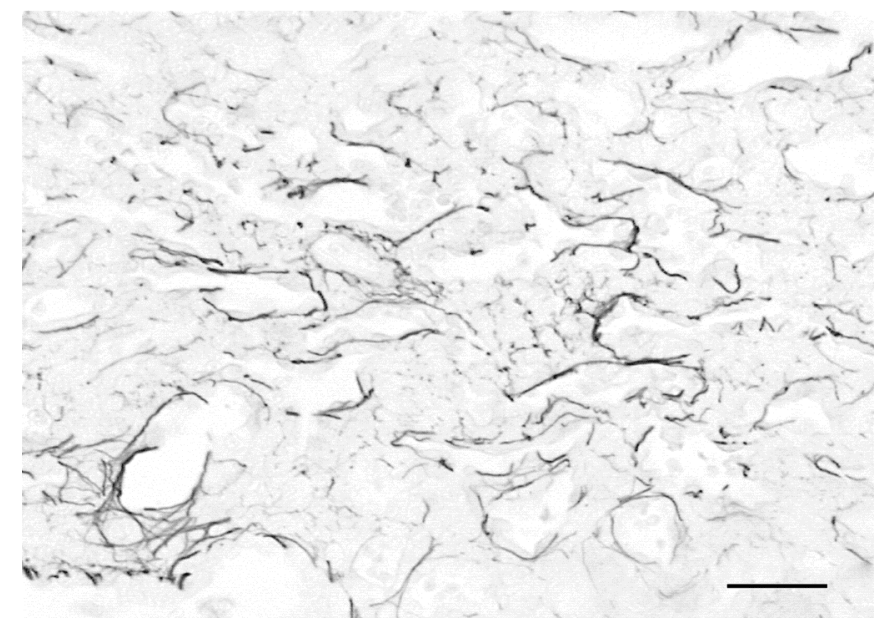

Fig. (2). Histological image from a foetal lung on the 19th day of gestation stained by Gomori method. Elastic fibers are well developed and surround the primitive saculli. Barr $=10 \mu \mathrm{m}$.

\section{Elastic Fibre Quantification by Image Analysis}

The results of the quantification of the fractional area occupied by the elastic fibres for each analysed day are shown in Fig. (3). 


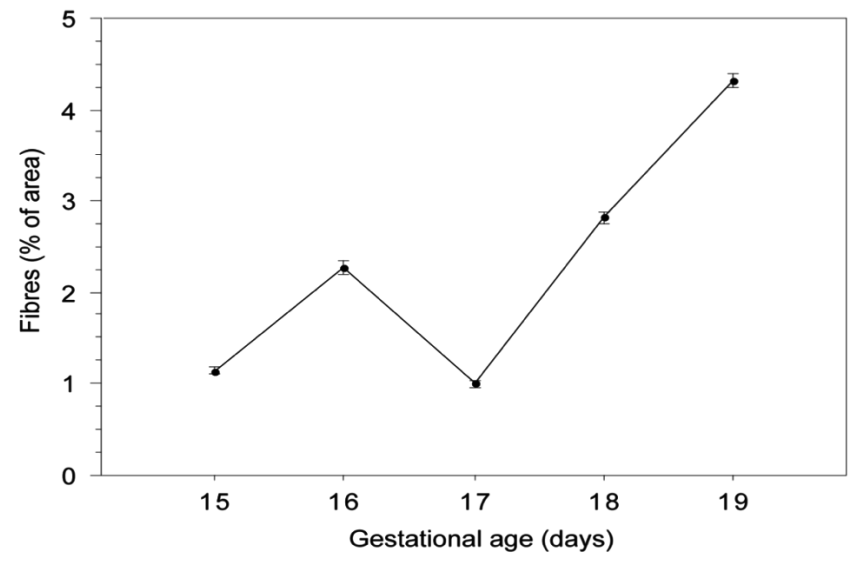

Fig. (3). Quantification by image analysis of the area occupied by elastic fibres in lungs from foetal mice between the 14th and the 19 th days of gestation. Data for each day is the mean \pm SE value of 20 image measurements acquired from 4 lungs from 2 different litters.

\begin{tabular}{|c|c|c|c|c|}
\hline 15 th & 16 th & 17 th & 18 th & 19 th \\
\hline 1.14 & 2.266 & 1.002 & 2.823 & 4.326 \\
$(0.033)$ & $(0.073)$ & $(0.032)$ & $(0.06)$ & $(0.074)$ \\
\hline
\end{tabular}

Age effect $p<0.0001$.

By the $15^{\text {th }}$ gestational day pulmonary elastic fibres correspond in mean to $1.14 \%$ of the total area of the fields observed, a figure that almost duplicates in the lungs from 16 day-old foetuses. At day 17 there was an abrupt decrease in the elastic fibre area, decreasing from about $2.23 \%$ to only $1.00 \%$ of the analysed microscopical fields. From this day onwards, there was a consisting increase in the elastic fibre fractional area which reached $4.33 \%$ on the last gestational day. The multiple comparison tests revelled significant differences $(p<0,0001)$ between values of all analysed days except for the pair 15 th-17th day.

The results of the quantification of the fractional area of the pulmonary tissue during pre-natal development are represented in Fig. (4).

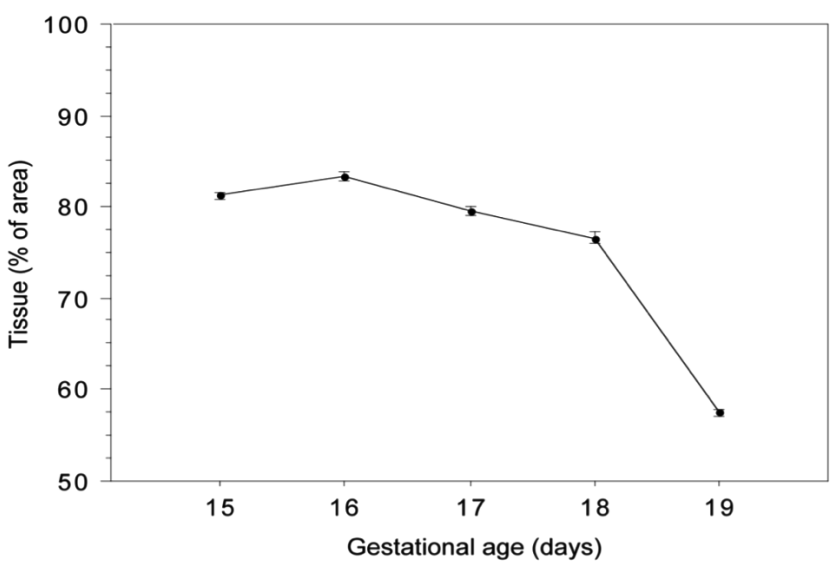

Fig. (4). Quantification by image analysis of the area occupied by pulmonary tissue in lungs from foetal mice between the 15 th and the 19th days of gestation. Data for each day is the mean \pm SE value of 20 image measurements acquired from 4 lungs from 2 different litters.

\begin{tabular}{|c|c|c|c|c|}
\hline 15 th & 16th & 17th & 18th & 19th \\
\hline 81,293 & 83.356 & 79.773 & 76.618 & 57.561 \\
$(0.384)$ & $(0.590)$ & $(0.443)$ & $(0.611)$ & $(0.393)$ \\
\hline
\end{tabular}

Age effect $p<0.0001$.

As one can see, there was a consistent reduction of the pulmonary tissue area from day 16 onwards, a slight one for the first two analysed days $(p=0,07)$, and then remaining prominent for the rest of gestation $(p \leq 0.002)$. The analysis of the elastic fibres' volumetric density during gestation, i.e., the relative area of pulmonary tissue that is occupied by elastic fibres, is shown in Fig. (5). At the $15^{\text {th }}$ gestational day, the elastic fibres in foetal lungs occupied about $1.40 \%$ of lung's tissue, a figure that went as high as $7.52 \%$ by the end of gestation. It should be stressed that by the $17^{\text {th }}$ day of gestation there was a sudden decrease in the relative amount of elastic fibres, their volumetric density reaching values close to the ones observed by day $15(p=0,86)$. As expected, there was a strong positive correlation, $(r=0.99)$, between the absolute and the relative amount of elastic fibres.

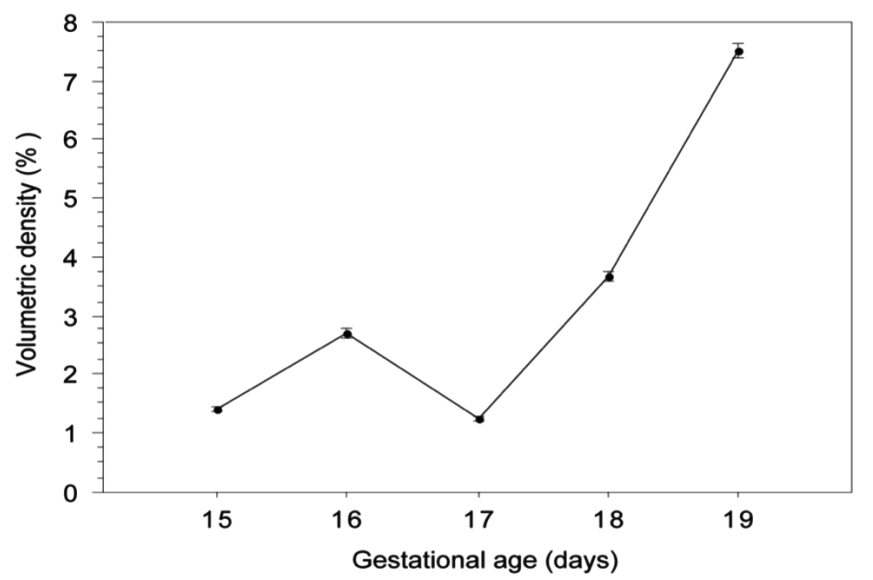

Fig. (5). Quantification by image analysis of the volumetric density of elastic fibres in lungs from fetal mice between the 14th and the 19 th days of gestation. Data for each day is the mean value of 20 image measurements acquired from 4 lungs from 2 different litters. Age effect $p<0.0001$.

\section{Desmosine and Isodesmosine Quantification by HPLC}

The biochemical quantification of desmosine and isodesmosine from the $15^{\text {th }}$ to the $19^{\text {th }}$ gestational days can be seen in Fig. (6). The values are expressed in pmols of desmosine and isodesmosine per mg of lungs, wet weight. Since there is evidence that there occurs a several-day delay between tropoelastin deposition and the conclusion of crosslinking with the formation of mature elastin [20-22] we report our results in quantity of desmosines without converting them to elastin equivalents.

The multiple comparison tests revealed significant differences $(p \leq 0.006)$ between values of all the days analysed, including the 15th-17th day pair, although it presented the smallest significative difference $(p=0.006)$.

There was a strong positive correlation between the desmosines concentration values obtained by HPLC and elastic fibres volumetric density determined by image analysis 


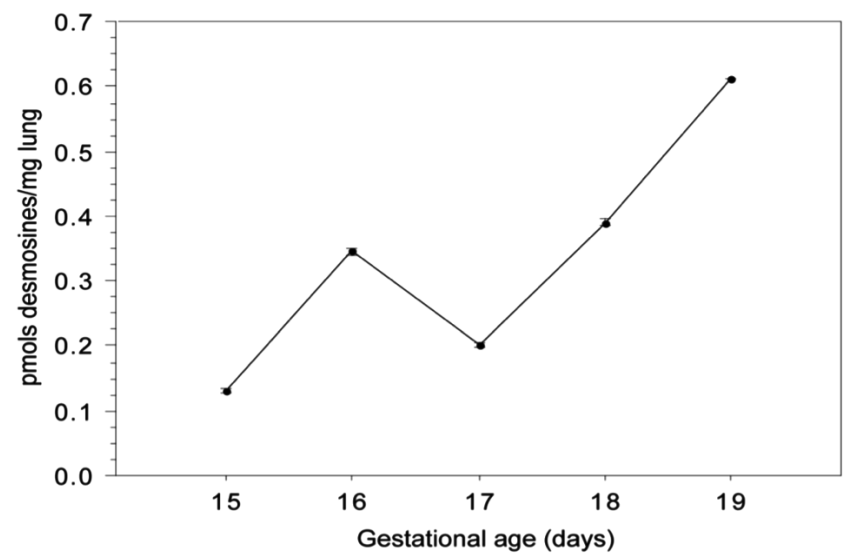

Fig. (6). Quantification by HPLC of desmosines concentrations (per wet weight) in mice foetal lung between the 15th and the 19th days of gestation. Data for each day is the mean \pm SE value of 3 consecutive determinations from a pool of lungs representing 23 to 34 individuals.

\begin{tabular}{|c|c|c|c|c|}
\hline 15 th & 16 th & 17 th & 18 th & 19 th \\
\hline $0.131(0.005)$ & $0.345(0.006)$ & $0,203(0.004)$ & $0.391(0.004)$ & $0.611(0.001)$ \\
\hline
\end{tabular}

Age effect $p<0.05$.

$(r=0,97)$. The coefficient of determination $\left(\mathrm{r}^{2}\right)$ of the regression analysis "concentration of desmosines vs volumetric density of elastic fibres" was 0.934 (Fig. 7).

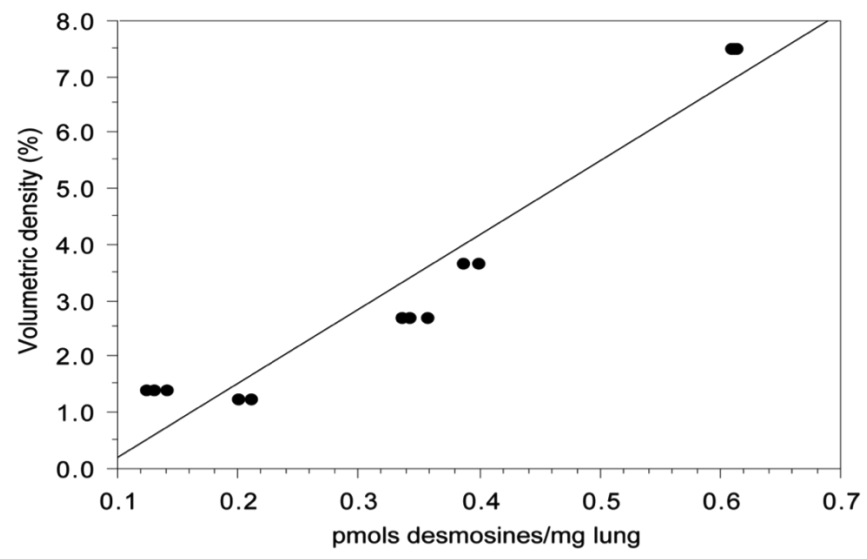

Fig. (7). Linear regression analysis of the results of quantification of elastin obtained by image analysis and HPLC. There is a significant linear correlation between the two methods $(y=-1.13+13.23 x$; $\left.r^{2}=0.93 ; p<0,0001\right)$.

\section{DISCUSSION}

Elastic fibres are an essential element not only in respiratory physiology, but also for the lung's perinatal morphogenesis $[1,5,10,23]$. The complete disruption of tropoelastin gene expression results in defective lung development, with distal branching defects and emphysematosous-like morphology, as well as a $100 \%$ postnatal mortality [6].

In this study we carried out a quantitative evaluation pulmonary elastic fibre of the mouse development from the $15^{\text {th }}$ till the $19^{\text {th }}$ gestational days, a period that comprises the later stage of the pseudoglandular phase, the canalicular phase and the beginning of the terminal sac period [13].
Because of the elastic fibres' physical and biochemical characteristics, namely their hydrophobic nature, insolubility and the heterogeneous and complex nature of the microfibrillar component and associated elements, the biochemical quantification of elastin is considered technically hard and poorly reproducible $[5,24]$. The methodology here described proved reliable although time and sample wasting. Because of the small size of the mouse foetal lung and its expected elastin-poor content, a pool of lungs was made for each day analysed, rendering it impossible to analyse the variability between individuals. However, the variability and distribution parameters used for the data obtained from the image analysis quantification revealed low inter-animal and interlitter differences. This fact should reflect in part the systematized management of the animals and of experimental procedures throughout the essay.

The staining method chosen for image analysis enabled a fine discrimination of the elastic fibres, so that the image analysis system was able to capture and process only what was intended for quantification. This technique combines morphology and quantity and allowed us to separate the elastic fibres system of the developing pulmonary tree from the elastic tissue present in the main lobar vessels, which proved impossible by the chemical method. We should emphasize that the staining principle of elastic fibres is related to the hydrophobic sequences of tropoelastin and elastin molecules, which are not involved in cross-linking [25], whereby the elastic fibre degree of maturation should not interfere with its quantification.

During the period analysed, one could notice a continuous increase in the elastic fibre area's fraction and volumetric density, which was particularly intense on the last two days of pregnancy, and disturbed only by a sudden and unexpected decrease on the $17^{\text {th }}$ gestational day, when elastic fibre levels fell to values close to the ones obtained at the $15^{\text {th }}$ day. This data was confirmed by the HPLC quantification of desmosines. Thus, we can assume that in foetal mouse lungs an elastolitic process occurs between the 16 and 17 days, which agrees with the morphological characteristics of the fibres at this day - sparse and fragmented-looking. During the lung's morphogenesis there is a time and spaceregulated expression of several matrix metalloproteinases (MMP). Although most studies concentrate on the role of MMPs in tubular basement membrane and vascular remodelling [26-29], we cannot forget that several of these enzymes, such as MMP-2, MMP-3, MMP-7, MMP-9 and MMP-12, have elastolytic properties $[30,31]$. During the $17^{\text {th }}$ day, the foetal lung suffers a major remodelling process, with an intense tubular branching that is characteristic of the tubular phase, as well as intense cellular activity preliminary to the sacular phase [32]. In this context it is not surprising that some of the MMP-activity and these enzymes released near to tubular basement membranes also hydrolyse the nearby elastic fibres.

By the end of gestation, we could observe a remarkable increase in pulmonary elastic fibres. This data agrees with previous reports $[6,9,12,33,34]$, relating both biochemical quantification [33] and in situ hybridisation to tropoelastin mRNA $[6,9,12,34]$, made in different species. 
In a previous work, we reported the quantification of elastin in mice during the alveolization period, from postnatal day 0 until the $21^{\text {st }}$ day of life [14]. The data presented here refers to the pre-natal elastogenesis of lung and, as we can see, from the $15^{\text {th }}$ day of gestation onwards lung elastin content undergoes great daily variations, due to the remodelling and growth of the respiratory tree and to the epithelialmesenchymal interactions and possibly to the matrix metalloproteinases's synthesis and activity, a matter that points towards the need for further research in the near future.

\section{REFERENCES}

[1] Fukuda Y, Ferrans VJ, Crystal RG. Development of elastic fibers of nuchal ligament, aorta, and lung of fetal and postnatal sheep: an ultrastructural and electron microscopic immunohistochemical study. Am J Anat 1984; 170: 597-629.

[2] Bruce MC, Honaker CE. Transcriptional regulation of tropoelastin expression in rat lung fibroblasts: changes with age and hyperoxia. Am J Physiol 1998; 274: L940-L950.

[3] Burri PH. Postnatal development and growth. In: Crystal RG, West JB, Barnes PJ, Cherniack NS, Weibel ER, eds. The lung: Scientific Foundations. New York: Raven Press; 1991; 677-687.

[4] Buckingham K, Heng-Khoo CS, Dubick M, et al. Copper deficiency and elastin metabolism in avian lung. Proc Soc Exp Biol Med 1981; 166: 310-319.

[5] Rucker RB, Dubick MA. Elastin metabolism and chemistry: potential roles in lung development and structure. Environ Health Perspect 1984; 55: 179-191.

[6] Wendel DP, Taylor DG, Albertine KH, Keating MT, Li DY. Impaired distal airway development in mice lacking elastin. Am J Resp Cell Mol Biol 2000; 23: 320-326.

[7] Kostka G, Giltay R, Bloch W, et al. Perinatal lethality and endothelial cell abnormalities in several vessel compartments of fibulin-1deficient mice. Mol. Cell Biol 2001; 21: 7025-7034.

[8] Nakamura T, Lozano PR, Ikeda Y, et al. Fibulin-5/DANCE is essential for elastogenesis in vivo. Nature 2002; 415: 171-175.

[9] Davidson J, Shibahara S, Schafer M, et al. Elastin mRNA levels during foetal development of sheep nuchal ligament and lung. Biochem J 1984; 220: 653-663.

[10] Noguchi A, Firsching K, Kursar JD, Reddy R. Developmental changes of tropoelastin synthesis by rat pulmonary fibroblasts and effects of dexamethasone. Pediatr Res 1990; 28: 379-82.

[11] Pierce RA, Mariani TJ, Senior RM. Elastin in lung development and disease. Ciba Found Symp 1995: 199-214.

[12] Antipatis C, Ashworth CJ, Grant G, Lea RG, Hay SM, Rees WD. Effects of maternal vitamin A status on fetal heart and lung: changes in expression of key developmental genes. Am J Physiol 1998; 275: L1184-L1191.

[13] Have-Opbroek T. Lung development in the mouse embryo. Exp Lung Res 1991; 17: 111-130.

[14] Gonçalves C, Barros J, Honório A, Rodrigues P, Bairos V. Quantification of elastin from mouse lung during postnatal development. Exp Lung Res 2001; 27: 533-545.

[15] Gomori G. Aldehyde-Fucsin: a new stain for elastic tissue. Am J Clin Pathol 1950; 20: 665-666.
[16] Bolender RP, Hyde DM, Dehoff RT. Lung morphometry: a new generation of tools and experiments for organ, tissue, cell, and molecular biology. Am J Physiol 1993; 265: L521-L549.

[17] Skinner SJM. Rapid method for the purification of the elastin cross-links desmosine and isodesmosine. J Chromatogr 1982; 229: 200-204.

[18] Fitch SM, Harkness MLR, Harkness RD. Extraction of collagen from tissues. Nature 1955; 176: 163.

[19] Guida E, Codini M, Palmerini CA, Fini C, Lucarelli C, Floridi A Development and validation of a high-performance liquid chromatographic method for the determination of desmosines in tissues. J Chromatogr 1990; 507: 51-57.

[20] Partridge SM, Elstden DF, Thomas J. Biosynthesis of the desmosine and isodesmosine cross-bridges in elastin. Biochem J 1964; 93 : 30c-33c.

[21] Partridge SM, Elstden DF, Thomas J. Incorporation of labelled lysine into the desmosine cross-bridges in elastin. Nature 1966; 209: 399-400.

[22] Campagnone R, Regan J, Rich CB, Miller M, Keene DR, Sakai L, Foster JA. Pulmonary fibroblasts: a model system for studying elastin synthesis. Lab Invest 1987; 56: 224-30.

[23] Noguchi A, Reddy R, Kursar JD, Parks WC, Mecham RP. Smooth muscle isoactin and elastin in fetal bovine lung. Exp Lung Res 1989; 15: 537-552.

[24] Sandberg L, Pollman M, Price L, et al. In: Tamburro AM, Davidson JM, eds. Elastin: chemical and biological aspects. Galatina: Congedo editore; $1990 ; 21-44$.

[25] Prentø P. A contribution to the theory of biological staining based on the principles for structural organization of biological macromolecules. Biotech Histochem 2001; 76: 137-161.

[26] Fukuda Y, Ishizaki M, Okada Y, Seiki M, Yamanaka N. Matrix metalloproteinases and tissue inhibitor of metalloproteinase-2 in fetal rabbit lung. Am J Physiol Lung Cell Mol Physiol 2000; 279: L555-L561.

[27] Reponen P, Sahlberg C, Huhtalat P, Hurskainen T, Thesleff I, Tryggvason K. Molecular cloning of murine $72-\mathrm{kDa}$ type IV collagenase and its expression during mouse development. J Biol Chem 1992; 267: 7856-7862.

[28] Rolland G, Xu J, Dupret JM, Post M. Expression and characterization of type IV collagenases in rat lung cells during development Exp Cell Res 1995; 218: 346-350.

[29] Rolland G, Xu J, Tanswell AK, Post M. Ontogeny of extracellular matrix gene expression by rat lung cells at late fetal gestation. Biol Neonate 1998; 73: 112-120.

[30] Mecham RP, Broekelmann TJ, Fliszar CJ, Shapiro SD, Welgus HG, Senior RM. Elastin degradation by matrix metalloelastases. J Biol Chem 1997; 272: 18071-18076.

[31] Lenz O, Elliot SJ, Stetler-Stevenson WG. Matrix metalloproteinases in renal development and disease. J Am Nephrol 2000; 11: 574-581.

[32] Cardoso WV. Lung morphogenesis revisited: old facts, current ideas. Dev Dyn 2000; 219: 121-130.

[33] Schellenberg JC, Liggins GC, Stewart AW. Growth, elastin concentration, and collagen concentration of perinatal rat lung: effects of dexamethasone. Pediatr Res 987; 21: 603-607.

[34] Pierce R, Kolodziej M, Parks W. Glucocorticoids upregulate tropoelastin during late stages of fetal lung development. Am J Physiol 1995; 268: L491-L500. 